\title{
IX. On the principles of equilibrium, and the stability of floating bodies applied to river and canal boats of different forms. Communicated by the author
}

\author{
Mr. John George English
}

To cite this article: Mr. John George English (1798) IX. On the principles of equilibrium, and the stability of floating bodies applied to river and canal boats of different forms. Communicated by the author, Philosophical Magazine Series 1, 1:4, 393-398, DOI: $10.1080 / 14786447808676856$

To link to this article: http://dx.doi.org/10.1080/14786447808676856

曲 Published online: 25 Jan 2010.

Submit your article to this journal $₫$

凹 Article views: 3

Q View related articles $\sqsubset$ 
IX. On the Principles of Equilibrium, and the Stability of foating Bodics applied to River and Canal Boats of different Forms. By Mr. Joh n George English, Teacbar of Matbematics and Mecbanicul Pbilojopby. Communicated by the Autbor.

$\mathrm{T}$

$\mathrm{HE}$ principles of dynamics in general, and of ftatics in particular, have already been fo fully explained by fome of the ablef mathematicians in Europe, that little or nothing of confequence is further to be expected on thofe fubjects, unlefs our mode of calculus be either greatly improved or totally changed. And as neither of thefe events is likely foon to take place, we ought certainly, in the mean time, to apply to the common concerns of life the principles of which we are already in poffefion. But fince war and merchandife feem at prefent to be the chief bufinefs of all European nations, and fince neither the one nor the other can be carried on to any great extent without navigation, nor can any veffel with $f_{d} f e t y$ be navigated without a proper degree of ftability; it is therefore a matter of the greateft importance to determine with accuracy the ftability of nautical veffels of all kinds.

However operofe and difficult the neceffary calculations may in fome cafes become before the degree of this effential quality can be obtained, yet they all depend upon the four following fimple and obvious theorems, accompanied with other well known ftereometrical and ftatical principles.

Tнеовед I. Every floating body difplaces a quantity of the fluid in which it floats, equal to its own weight: and confequently, the fpecific gravity of the fluid will be to that of the floating body, as the magnitude of the whole is to that of the part immerfed.

THEOREM II. Every floating body is impelled downward by its own effential power, acting in the direction of a vertical line paffing through the centre of gravity of the whole; 
whole; and is impelled upward by the reaction of the fluid which fupports it, acting in the direction of a vertical line paffing through the centre of gravity of the part immerfed : therefore, unlefs thefe two lines are coincident, the floating body thus impelled muft revolve round an axis, either in motion or at reft, until the equilibrium is reftored.

THEOREM III. If by any power whatever a veffel be deflected from an upright pofition, the perpendicular diftance between two vertical lines paffing through the centres of gravity of the whole, and of the part inmerfed refpectively, will be as the ftability of the veffel, and which will be pofitive, nothing, or negative, according as the metacentre is above, coincident with or below, the centre of gravity of the veffel.

THEOREM IV. The common centre of gravity of any fyftem of bodies beingigiven in pofition, if any one of thefe bodies be moved from one part of the fyltem to another, the correfponding motion of the common centre of griwity, eftimated in any given direction, will be to that of the aforefaid body, eftimated in the fame direction, as the weight of the body moveck is to that of the whole fyftem.

From whence it is evident, that in order to afcertain the ftability of any veffel, the pofition of the centres of gravity of the whole, and of the partimmerfed mutt be determined; with which, and the dimenfions of the veffel, the line of floatation, and angle of deflection, the ftability or power cither to right itfelf or overturn may be found.

In thips of war and merchandife, the calculations neceffary for this purpofe become unavoidably very operofe and troublefome; but they may be much faciliated by the experimental method pointed out in the New Tranfactions of the Swedith Academy of Sciences, firft quarter of the year 1787 page 48 .

In river and canal boats, the regularity and fimplicity of the form of the veffel itfelf, together with the compact difpofition and homogeneal quality of the burden, render that method for them unneceffary, and make the requifite calcu- 
lations become very eafy. Veffels of this kind are generally of the fame tranfverfe fection throughout their whole length, except a finall part in prow and ftern, formed by fegments of circles or other fimple curves; therefore a length may eafily be affigned fuch, that any of the tranfverfe fections being multiplied thereby, the product will be equal to the whole folidity of the veffel. The form of the fection $A B C D$ is for the moft part either rectangular as in fig. I. (Plate XIII.), trapezoidal as in fig. 2. or mixtilineal as in fg. 3. in all which MM reprefents the line of floatation when upright, and EF that when inclined at any angle MXE; alfo $G$ reprefents the centre of gravity of the whole veffel, and $R$ that of the part immerfed.

If the veffel be loaded quite up to the line $A B$, and the Ipecific gravity of the boat and burden be the fame, then the point $\mathbf{G}$ is fimply the centre of gravity of the fection $A B C D$; but if not, the centres of gravity of the boat and burden munt be found feparately, and reduced to one by the common method, namely, by dividing the fum of the momenta by the fum of weights, or areas, which in this cafe are as the weights. The point $R$ is always the centre of gravity of the fection $M M C D$, which, if confifting of different figures, mut alfo be found by dividing the fum of the momenta by the fum of the weights as common. Thefe two points being found, the next thing neceffary is to determine the area of the two equal triangles $\mathrm{MXE}, \mathrm{MXF}$, their centres of gravity 0,0 , and the perpendicular projected diftance $n n$ of thefe points on the water line EF. This being done, through $R$ and parallel to $E F$ draw $R T=a$ fourth proportional to the whole area $\mathrm{MMCD}$, either triangle $\mathrm{MXE}$ or $\mathrm{MXF}$, and the diftance $n n$; through $T$, and at right angles to $\mathrm{RT}$ or $\mathrm{EF}$, draw $\mathrm{TS}$ meeting the vertical axis of the veffel in $S$ the metacentre; alfo through the points $G, B$, and parallel to $S T$, draw N GW and $B V$; moreover through $S$, and parallel to $E F$, draw W S V meeting the two former in $V$ and $W$; then $S W$ is 


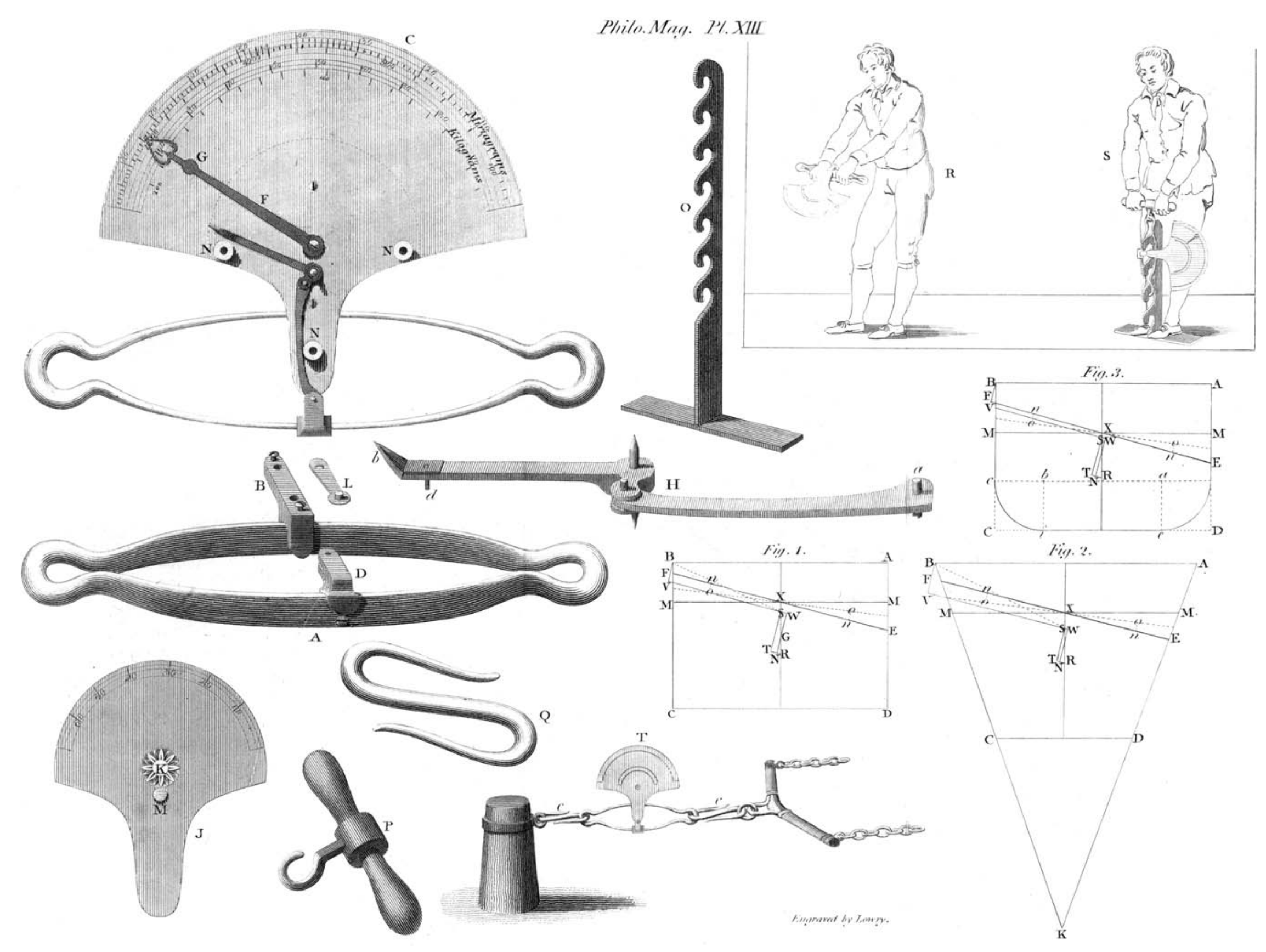


as the ftability of the veffel, which will be pofitive, nothing, or negative, according as the point $S$ is above, coincident with, or below, the point $G$. If now we fuppofe $W$ to reprefent the weight of the whole veffel and burden (which will be equal to the fection $M M C D$ multiplied by the length of the veffel), and $P$ to reprefent the required weight applied at the gunwale $B$ to fuftain the veffel at the given angle of inclination; we thall always have this proportion : as VS : SW : : W : $\mathrm{P}$; which proportion is general, whether SW be pofitive or negative; it muft only in the latter cafe be fuppofed to act upward to prevent and overturn.

In the rectangular veffel, of given weight and dimenfions, the whole procefs is fo evident, that any further explanation would be unnecefiary. In the trapezoidal veffel, after having found the points $G$ and $R$, let $A D, B C$ be produced until they meet in $K$. Then fince the two fections $M M C D, E F D C$ are equal, the two triangles $M M K$, E F $K$ are alfo equal; and therefore the rectangle $\mathrm{EK} \times$ $\mathrm{BF}=\mathrm{KM} \times \mathrm{KM}=\mathrm{KM}^{2}$; and fince the angle of inclination is fuppofed to be known, the angles at $\mathrm{E}$ and $\mathrm{F}$ are given. Confequently, if a mean proportional be found between the fines of the angles at $E$ and $F$, we thall have the following proportions:

As the mean proportional thus found : fine $\angle \mathrm{E}: \mathrm{:} \mathrm{KM}: \mathrm{KF}$, And as the faid mean proportional ; fine $\angle F:: K M: K E$; therefore $M E, M F$ become known; from whence the area of either triangle $\mathrm{MXE}$ or $\mathrm{MXF}$, the diftance $n n$, and all the other requifites may be found.

In the mixtilineal fection, let $A B=9$ feet $=108$ inches, the whole depth $=6$ feet $=72$ inches, and the altitude of M M the line of floatation 4 feet or 48 inches; alfo let the two curvilinear parts be circular quadrants of 2 feet, or 24 inches radius each. Then the area of the two quadrants $=$ 904.7808 fquare inches, and the diftance of their centres of gravity from the bottom $=13.8177$ inches very nearly; alf 
the area of the included rectangle $a b i e=1440$ fquare inches, and the altitude of its centre of gravity 12 inches; in like manner the area of the rectangle $\mathrm{AB} c d$ will be found $=5^{184}$ fquare inches, and the altitude of its centre of gravity 48 inches; therefore we fhall have

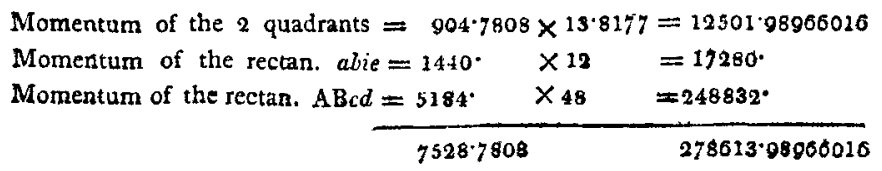

Now the fum of the momenta divided by the fum of the areas will give $\frac{278613.989^{66016}}{75^{28} \cdot 7808}=37.006$ inches, the altitude of $G$ the centre of gravity of the fection A B C D above the bottom. In like manner the altitude of $\mathbf{R}$ the centre of gravity of the fection M M CD will be found to be equal $\frac{123093^{\circ} 9^{8} 96606 \mathrm{I}}{493^{6} \cdot 7^{808}}=24^{\circ} 934$ inches; and confequently their difference, or the value of $G R=12.072$ inches, will be found.

Suppofe the veffel to heel $15^{\circ}$, and we thall have the following proportion, namely, As radius : tangent of $15^{\circ}:: \mathrm{MX}$ $=54$ inches : $14^{\circ} 469$ inches $=\mathrm{ME}$ or $\mathrm{MF}$; and confequently the area of either triangle $\mathrm{MXE}$ or $\mathrm{MXF}=$ 390.66 .3 fquare inches. Therefore, by theorem $4^{\text {th }}$, As $4936 \cdot 7808: 390663:: 72=n n=\frac{2}{3} \mathrm{AB}: 5.6975$ inches $=\mathrm{RT}$; and again, As radius : fine of $15^{\circ}:: 12.072=\mathrm{GR}$ : 3.1245 inches $=\mathrm{RN}$; confequently $\mathrm{RT}-\mathrm{RN}=5.6795-$ $3 \cdot 1245=2 \cdot 573$ inches $=\mathrm{S} \mathrm{W}$ the ftability required.

Moreover, As the fine of $15^{\circ}:$ radius : : $5.6975=\mathrm{RT}$ : $22 \cdot 013=\mathrm{RS}$, to which if we add 24.934 , the altitude of the point $R$, we thall have 46.947 for the height of the metacentre, which taken from 72 , the whole altitude, there remains $25^{\circ} 053$; from which and the half width $=54$ Inches, the diftance $B S$ is found $=59^{\circ} 529$ inches very nearly, 
nearly, and the angle $S B V=80^{\circ}-06^{\prime}-42^{\prime \prime}$; from wherce $\mathrm{SV}=5^{8 \cdot 645}$ inches.

Again : Let us fuppofe the mean length of the veffel to be 40 feet, or 480 inches, and we fhall have the weight of the whole veffel equal to the area of the fection $\mathrm{MMCD}=$ $4936 \cdot 7808$ multiplied by $480=2369654^{\circ} 784$ cubic inches of water, which weighs exactly 85708 pounds avoirdupoife, allowing the cubic foot to weigh 62.5 pounds.

And, finally, as S V : S W (i.e.)' as $58.645: 2.573$ : : $85708: 3760+$, the weight on the gunwale which will fuftain the veffel at the given inclination. Therefore a veffel of the above dimentions, and weighing 38 tons, 5 cwts. $28 \mathrm{lbs}$. will require a weight of 1 ton, $13 \mathrm{cwts}$. $64 \mathrm{lbs}$. to make her incline $15^{\circ}$.

In this example the deflecting power has been fuppofed to act perpendicularly on the gunwale at $B$; but if the veffel is navigated by fails, the centre velique muft be found; with which, and the angle of deflection, the projected diftance thereof on the line SV may be obtained; and then the power, calculated as above, neceffary to be applied at the projected point, will be that part of the wind's force which caufes the veffel to heel. And converfely, if the weight and dimenfions of the veffel, the area and altitude of the fails, the direction and velocity of the wind be given, the angle of deflection may be found.

X. New Metbod of freeing Molafjes from their Barp Tafte, and rendering them fit to be ufed infead of Sugar. From Crell's Chemical Annals, 1798, Vol. I. Part 2.

O

ADET DEVAUx, according to the experiments made by Lowitz, gives the following method: Take twenty-four pounds of molaffes, twenty-four pounds of water, and fix pounds of charcoal coarfely pulverifed; and having mixed them in a kettle, boil the whole over a now wood fire,

When 